\title{
Spinal Anaesthesia for Ambulatory and Short-Stay Plastic Surgery Procedures
}

\author{
Víctor M. Whizar-Lugo, Juan C. Flores-Carrillo, \\ Susana Preciado-Ramírez, Jaime Campos-León and \\ Víctor Silva
}

Additional information is available at the end of the chapter

http://dx.doi.org/10.5772/58407

\section{Introduction}

Outpatient and short-stay plastic surgery procedures have increased recently up to $457 \%$ [1] due to lower prices, global availability of plastic surgeons, better and safer anaesthetic techniques. This exponential growth has been increased by greater information in the media, most notably by means of the enlightenment shown in the internet. Every day more complex patients force anaesthesiologists to develop better techniques using multimodal approaches before, during and after anaesthesia. Nowadays it is possible to perform ambulatory plastic surgery procedures in people with medical conditions that in the past were rejected; myocardial ischemia, arrhythmias, hypertension, coagulation disorders, lung diseases, diabetes, etcetera. Improved safety and efficacy in all anaesthesia procedures for plastic surgery is mandatory; surgeons, patients, relatives and media have their own concerns regarding anaesthesia patient safety.

Local anaesthesia, plexus nerve blocks and neuroaxial techniques have been reported with excellent results, as well as patient comfort and acceptance. Spinal, epidural or combined spinal-epidural procedures are quite safe and have attained widespread use for patients undergoing ambulatory surgery below the Th3-Th4 spinal level. Spinal anaesthesia for outpatient and short-stay plastic surgery cases have been well accepted by surgeons and patients due to its rapid onset and offset, easy administration, minimal expenses, and almost no side effects or complications. Ambulatory procedures as liposuction, buttocks implants and calf implants, and many more are done properly under spinal anaesthesia. Longer surgeries like abdominoplasty, lower body lift, or combined surgeries involving upper and lower body segments are also done safely under subarachnoid or epidural anaesthesia.[2,3,4] Small gauge pencil point needles have acceptable rates of 0 to $3 \%$ of postdural puncture headache (PDPH); 
the most fearful side effect of spinal anaesthesia. There are several choices of local anaesthetics (LAs) available for spinal anaesthesia for ambulatory and short-stay patients, including ropivacaine, levobupivacaine, racemic bupivacaine, prilocaine, mepivacaine, articaine, procaine and chloroprocaine. Although controversial, lidocaine is no longer recommended to be used for spinal anaesthesia. Intraspinal adjuvant drugs like clonidine, dexmedetomidine, morphine, sufentanyl and fentanyl enhance quality and duration of spinal blocks.

Deep venous thrombosis and pulmonary embolism remains the greatest cause of morbidity and mortality in plastic surgery.[5,6,7] Spinal anaesthesia decreases these complications as it facilitates early ambulation. Postoperative pain can be managed with preoperative preemptive analgesia techniques, plus adjuvant drugs injected into the spinal space.

For the purposes of this review we define outpatient surgery cases as those who are discharged the same day of the procedure, and short-stay patients those who remain in the surgical unit or hospital for 24 hours after surgery. This chapter reviews the indications, contraindications, advantages, disadvantages and drugs used for spinal anaesthesia in ambulatory and shortstay plastic surgery procedures.

\section{Subarachnoid anaesthesia techniques}

There are three ways to perform spinal anaesthesia; single injection, combined spinal-epidural, and continuous subarachnoid anaesthesia with small gauge spinal catheters.

Single injection. Is the most widely used since it is easy to perform, safe, predictable, has low incidence of side effects, and low cost. The addition of adjuvants drugs to LAs provides sufficient time for more prolonged plastic surgical procedures, and therefore is the ideal technique in these patients.[3]

Combined spinal/epidural. Combines the benefits of epidural and subarachnoid anaesthesia, lessening some of the disadvantages of both procedures. This technique allow us to titrate the upper sensory level, to reduce total dose of epidural LAs, and to continue anaesthesia as long as needed.[8,9] It is recommend for long plastic surgeries involving chest, abdomen and extremities in the same patient. Sometimes it is difficult to keep the epidural catheter in place, and it can also migrate outside the epidural space.[10,11]

Continuous spinal anaesthesia. Described by Dean in 1907 [12] was reintroduced by Lemmon in 1940 [13]. The technique had several modifications until Hurley and Lambert [14] introduced the use of thin spinal microcatheters 32-gauge. Nowadays this procedure is underutilized due to several cases of cauda equina syndrome and the FDA recommendation to withdraw the technique. The main advantages of continuous spinal anaesthesia is to allow redosing of small amount of LA to prolong duration of anaesthesia/analgesia and provide better hemodynamic stability.[15] In the field of plastic surgery outpatient and short-stay cases it may be limited for older patients with prolonged procedures below Th8 dermatomes.

Spinal anesthesia is done following anatomical landmarks. The introduction of ultrasound in regional anesthesia is an advanced technique that is now used in difficult cases where anatomy 
cannot be identified properly, or when a difficult block is anticipated as in morbidly obese or patients with severe anatomic alterations.

\section{Indications of spinal anaesthesia}

There are two groups of patients who desire plastic surgery procedures: a) Those who undergo surgery for purely aesthetic reasons to look better and b) Those who do it for work, social or professional demands. These are patients with special wishes and needs that most of the times border on perfection, therefore they have poor tolerability for errors or side effects. Complications from anaesthesia are not tolerable, even small or insignificant side effects are not accepted. These patient characteristics demand a careful anaesthesiologist, a cautious anaesthetic plan with some management alternatives ready to be use in order to stay away from mistakes and complications.

Typically spinal anaesthesia is used for surgical procedures below dermatome Th10, involving the abdomen, pelvis, perineum, and lower extremities. Outpatient and short-stay plastic surgery procedures localized up to dermatome Th3-Th4 can be safely done under lumbar spinal anaesthesia, tilting the surgery table in Trendelemburg or reverse Trendelemburg position until the desired surgical level is reached. For example, you can use lumbar subarachnoid block for breast surgery and chest/back liposuction, or abdominoplasty combined with breast surgery.[16,17]

Tables 1 and 2 show our recommendations for outpatient and short-stay cosmetic surgery procedures that can be done under spinal anaesthesia, including surgeries up to Th3-Th4 dermatomes. In some circumstances it is convenient to use combined epidural-intrathecal anaesthesia to ensure sufficient anaesthetic duration, as discussed previously.

\begin{tabular}{|c|c|c|c|c|c|c|}
\hline \multirow{2}{*}{ Surgery } & \multicolumn{2}{|l|}{ Spinal } & \multicolumn{2}{|l|}{ Epidural } & \multicolumn{2}{|c|}{ Spinal-epidural } \\
\hline & Anaesthetic & Adjuvant & Anaesthetic & Adjuvant & Anaesthetic & Adjuvant \\
\hline Liposuction & $\mathrm{L}, \mathrm{PPX}$ & $C, F$ & L, PPX & $C, F$ & $\mathrm{~L}, \mathrm{PPX}$ & $C, F, S$ \\
\hline Liposculpture & L, PPX & $C, F$ & L, PPX & $C, F$ & L, PPX & $C, F, S$ \\
\hline $\begin{array}{l}\text { Buttock Implants/fat } \\
\text { grafting }\end{array}$ & L,PPX & $C$ & L, PPX & C & L, PPX & $C, F, S$ \\
\hline Calf Implants & L, PPX & $C$ & L, PPX & $C$ & L, PPX & $C, F, S$ \\
\hline $\begin{array}{l}\text { Breast and } \\
\text { liposuction }\end{array}$ & PPX & $C, F$ & L, PPX & $C, F$ & L, PPX & C.F.S \\
\hline Breast only & Not recomended & $\begin{array}{l}\text { Not } \\
\text { recomended }\end{array}$ & L, PPX & $\begin{array}{l}\text { Not } \\
\text { recomended }\end{array}$ & Not recomende & d Not recomended \\
\hline Perineal procedures & L, PPX & $C, F$ & L, PPX & $C, F$ & Not recomende & d Not recomended \\
\hline
\end{tabular}

Table 1. Ambulatory plastic surgery procedures and neuroaxial anaesthesia.[3] 


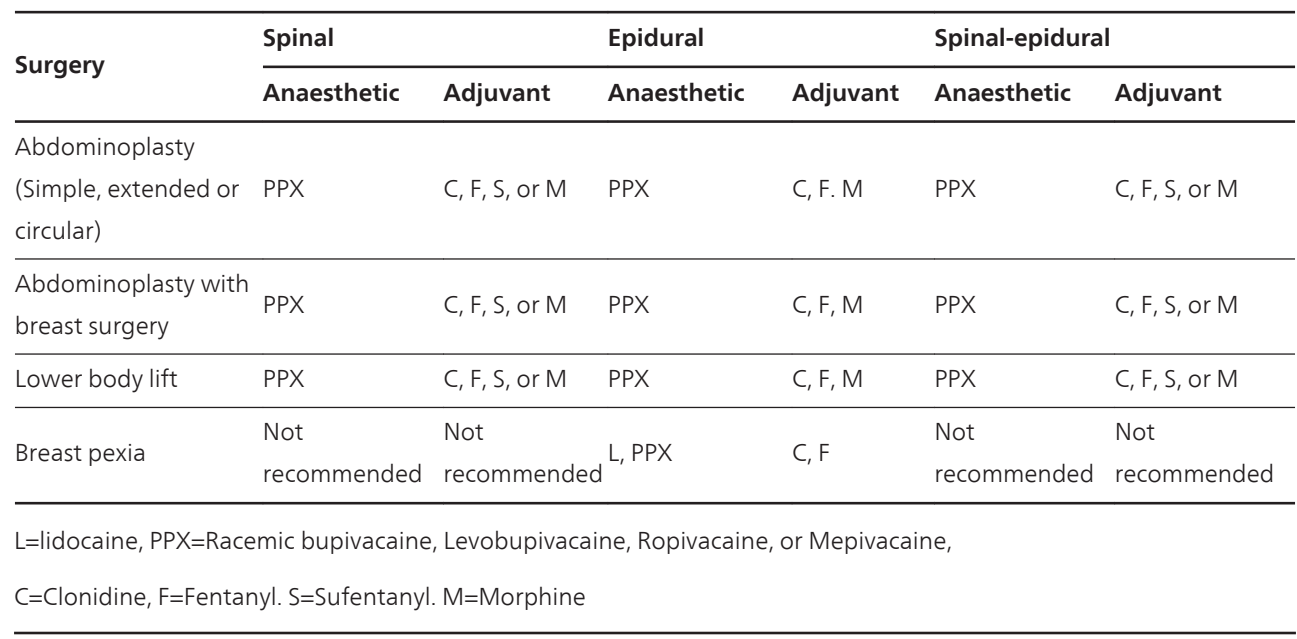

Table 2. Short-stay plastic surgery procedures and neuroaxial anaesthesia.[3]

\section{Contraindications for spinal anaesthesia}

Contraindications are divided into absolute and relative, as shown in table 3. Contraindications for spinal anaesthesia have been changed over time due to advanced equipment such small gauge pencil point spinal needles, small gauge Quincke type spinal needles, special tip designs spinal needles, recent LAs and adjuvants drugs. Patients who wish to fly few days after their surgery should not receive spinal anaesthesia because of the pressure changes in aircraft cabins may facilitate cerebrospinal fluid (CSF) leak through the duramater hole. In addition to these general contraindications, there are few situations where it is not advisable to use spinal anaesthesia in these patients. For example; patients who live far away from where they are operated and are not able or willing to return to this facility, should not receive spinal anaesthesia because the small risk of PDPH. This situation implies that they have to be treated by colleagues at their city of origin and could facilitate unnecessary medical legal problems. With plastic surgeons that require longer surgical times it is better to avoid spinal anaesthesia or advice the patients that they may need general anaesthesia near the end of the procedure.

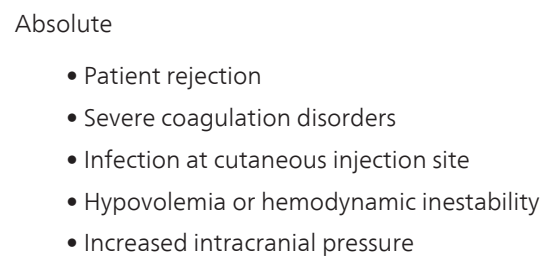




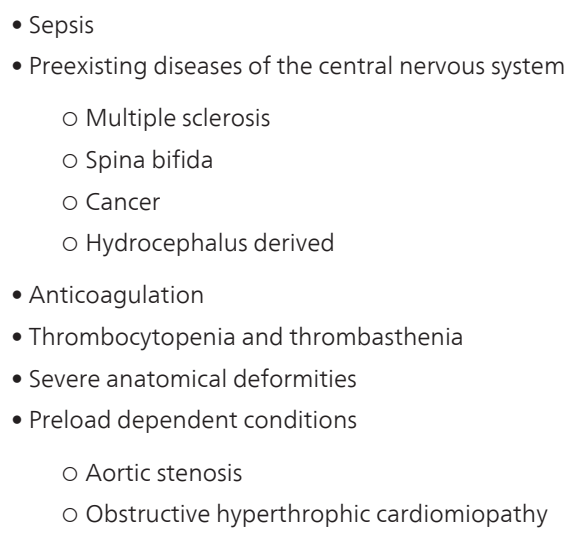

Table 3. Spinal anaesthesia contraindications

\section{Advantages and complications of spinal anaesthesia}

Subarachnoid anaesthesia is an easy procedure that provides a deep and fast surgical block through the injection of small dose of LA into the lumbar spinal space.[18,19] Even though lumbar volume of CSF is the main determinant of the effects produced by intrathecal injection of LA solutions, duration and spread of spinal anaesthesia can be easily manipulated with type/dose of LAs, baricity of the solution, as well as the addition of preservative free adjuvant drugs like opioids and/or alpha ${ }_{2}$-adrenergic agonists.[19,20] Although some aspects of this technique are controversial, nowadays it is known to be safer than epidural anaesthesia,[21] with many advantages over other anaesthetic procedures, fewer side effects and uncommon severe complications.

Advantages. Subarachnoid anaesthesia for ambulatory and short-stay plastic surgery patients is characterized by rapid onset and convenient offset, quick and simple administration, inexpensive, with minimal side effects and very few complications. It offers many advantages for this type of patients as it can be used for procedures below Th3-Th4 such as breast surgery, abdominal procedures, liposuction and many more surgeries (Tables 1 and 2). The use of small gauge pencil point spinal needles has reduced to $0-3 \%$ the incidence of PDPH, even in young and outpatients. Spinal anaesthesia is more predictable and safer than epidural or general anaesthesia. The likelihood of neural damage is reduced when compared to peripheral nerve blocks. Regional anaesthesia procedures, including subarachnoid anaesthesia, have better pain control, attenuation of the surgical stress response, preserve perioperative immune function, better preservation of oxygenation and pulmonary residual functional capacity, improved visceral vascular flow, early recovery of postoperative ileum, and reduced venous thrombotic disease and pulmonary embolism. 
Complications and disadvantages. Bradycardia and hypotension are the most frequent cardiovascular side effects associated with spinal anaesthesia and are related to the secondary sympathetic block. Total dose/volume of injected LAs have a direct relationship with the cardiovascular response. Bradycardia and arterial hypotension are easy to treat with intravenous fluids and vasoactive drugs. Sudden cardiac arrest is observed with an estimated incidence of 0.7 to $0.15 \%$.[22,23,24,25] Changing patient position and hypovolemia are factors related to sudden cardiac arrest, this situation can take place during extensive liposuction or abdominoplasty-liposuction. In these patients it is very important to use preventive treatment as well as to establish proper therapy immediately.

Nerve damage is the most feared side effect of spinal anaesthesia. It can be secondary to local neurotoxicity of LAs or adjuvant drugs, direct needle damage, haematoma or spinal infection. Cauda equina syndrome and transitory neurological symptoms (TNS) due to posterior nerve roots irritation at their entry to the spinal cord [26] are the most neurological controversial side effects. Several mechanisms have been proposed to explain them. Local neurotoxicity after spinal injection of any LA is an issue of concern raised after the first published data by Schneider.[27] Follow up of patients who received uncomplicated spinal anaesthesia had shown that some developed pain in the buttocks and/or lower extremities after an initial full recovery from spinal anaesthesia. This painful condition that occurs in the immediate postoperative period is known as TNS, and last up to 5 days. Numerous articles have been published showing that subarachnoid LAs are not free of neurotoxicity; all of them are neurotoxic when injected inside the spinal space, having a different grade of toxicity. $[27,28,29,30]$ Takenami et al [26] found in rats that supraclinical concentration of lidocaine initially is limited to the posterior roots at their entry to the spinal cord. Zong et al found that spinal ropivacaine $0.75-1.0 \%$ induced neurotoxicity after repeated injections in rats; infiltration of inflammatory cells, vacuolation of myelin sheaths and axons, abnormal morphology of neurons and apoptosis in the spinal cord, mainly in posterior roots and the adjacent posterior white matter.[31]

In summary, spinal lidocaine is the most neurotoxic LA, followed in descending order of toxicity by bupivacaine, levobupivacaine, ropivacaine, articaine, chloroprocaine and procaine.

Postdural puncture headache. This complication is no longer a major concern with a rate of 0 to 3\% when pencil point G-27 to G-25, Quincke point G-27,or special tip like Atraucan spinal needles are used. Even in younger outpatients who were considered at high risk for developing PDPH, this side effect is seldom observed.[32,33] Post dural puncture headache is attributed to CSF leak to the extradural space through the hole in the dura. Reina et al [34] found that G-25 Quincke needles produced well defined dural holes without inflammatory reaction, while the G-25 Whitacre needles leave a dural hole with separation and disruption of the collagen fibers and a inflammatory component. They argue that the edema that occurs by this inflammatory reaction is responsible for the closure of the dural hole, which clinically lowers the incidence of PDPH by preventing further loss of CSF. Post dural puncture headache can prolong the convalescence of patients and be a determining factor for hospital readmission. Seventy to $90 \%$ of patients have a spontaneous resolution in one to six weeks after dural puncture. Conservative management involves bed rest, fluids, analgesics and caffeine. 
Epidural blood patch is seldom needed for PDPH after subarachnoid anaesthesia done with pencil point needles.

Failed spinal. There are several factors to explain this malfunction; partial position of spinal needle tip into the subdural or epidural space, inadequate dose, expired LAs, injection into a dural sac appendix (Tarlov's cyst), low spinal tap, inadequate accumulation of hyperbaric LA in sacral roots, and on occasions when surgery is prolonged beyond the time of the spinal anaesthesia.[35] When a subarachnoid block fails, 20-30 minutes must elapse before it is repeated so as to avoid the possibility of additive effects over the first dose of LA. It is important to be sure that the first injected LA has reached its maximum effect, if any. Remember that the spread of LAs may be very slow in some patients, therefore a waiting time of 20 to 30 minutes ensures that most of the LA which access the subarachnoid space is fixed in the neural tissue. The second injection done at the same space, or even better in upper spaces, usually produces a proper subarachnoid block. It has been recommended not to use opioids during the second attempt (if opioids were used in the first attempt) to avoid eventually delayed respiratory depression. It is also wise not to use vasoconstrictors in the second injection that could lead to severe nerve damage by ischemia.[36,37] The addition of clonidine might be safe during the second spinal block as intratecal doses of this drug are very wide (30 to $450 \mu \mathrm{g}$ ).

Arachnoiditis. Recent studies on the incidence of arachnoiditis secondary to neuroaxial anaesthesia seems to point out this new entity as a ghost, as a deleterious effect that we must consider each time that a patient will undergo a neuroaxial injection. This entity may present initially as TNS, cauda equina syndrome or conus medullaris, and then evolve radiculitis, fibrosis, scarring of the dural sac, deformities, pachymeningitis, syringomyelia, and pseudomeningocele among others. It has been associated with neuroaxial anaesthesia after traumatic punctures, LAs, detergents, antiseptics, preservatives and other substances injected by accident or intentionally into the subarachnoid, subdural or peridural space.[38]

Total spinal block. It can happen during extradural block attempt with inadverted dural puncture and the injection of high volume of LAs. During spinal anaesthesia LAs seldom reach an unwanted high metameric level. This situation happens with inappropriate high doses of LAs, neglect manipulation of patient position when injected with hypo or hyperbaric LAs. If the level is too high, it may be accompanied by bradycardia, cardiac arrest and or respiratory failure requiring pharmacologic and ventilatory support.

Bleeding. The development of cerebral or spinal haematomas subsequent to spinal anaesthesia is a serious and rare complication which mandates prompt diagnosis, and immediate surgery. A closed claims study in Finland during 2000/2009 [22] found an incidence of neuroaxial haematoma after spinal anaesthesia of 1:775,000, which is lesser than epidural anaesthesia 1:26,400 and combined epidural-spinal 1:17,800. Castillo et al. in Catalonia Spain [39] reported an approximated incidence of one haematoma per 150,000 neuroaxial anaesthesias ( 0.6 per 100,000 spinal anaesthesias versus 0.7 per 100,000 epidural anaesthesias). When performing neuroaxial anaesthesia it is important to adhere to ASRA guidelines [40] avoiding regional anaesthesia in patients at risk of bleeding such as coagulation abnormalities, anticoagulation therapy. Remember that certain conditions like advanced age, anomalies of the vertebral column or spinal cord, and difficult neuroaxial blocks can increase the risk of bleeding. 
Trauma and infection. There have been reports of nerve damage by direct trauma produced by the spinal needle, and also there are reports of infections manifested as meningitis or epidural abscesses after neuroaxial anaesthesia. Instances of either occurrence are exceedingly uncommon.[25]

As reviewed in the previous paragraphs, severe complications secondary to spinal anaesthesia are extremely rare and therefore difficult to study. Auroy et al [25] in their prospective study conducted in France with 756 anaesthesiologists found that the incidence of deleterious events after regional anaesthesia were rare; they found only 98 incidents in 103,730 cases. There were 40,640 cases of spinal anaesthesia with cardiac arrest in 26 of whom 6 died, (6.4 1. 1.2./ 10,000 patients) which was significant $(p<0.05)$ when compare with other regional anaesthesia techniques. There were 21 neurological complications (radiculopathy, cauda equina syndrome, paraplegia). Two thirds of the patients with neurologic deficits had either a paresthesia during needle placement or pain on injection and $75 \%$ of the neurologic deficits after nontraumatic spinal anaesthesia occurred in patients who had received $5 \%$ hyperbaric lidocaine.

\section{Drugs for spinal anaesthesia}

There are two groups of drugs used for spinal anaesthesia; LAs and adjuvant drugs. The latter are used to enhance the performance of spinal anaesthesia and or to lower doses of LAs and their corresponding side effects. They can be injected through a spinal needle or multiple doses through a spinal catheter.

Systemic toxicity of LAs is not an issue in subarachnoid anaesthesia, since the dosages used are very small compared with the epidural doses. However, due to the increasing use of combined neuroaxial anaesthesia (subarachnoid-epidural) and injections of higher doses of lidocaine during liposuction, abdominoplasty or neck and face lift, it is important to bear in mind the possibility of systemic toxicity manifested by seizures, coma, arrhythmias, or heart failure.

The choice of the spinal LA is determined taking into account the type and duration of plastic surgery procedures, patient health condition, facilities where the operation is performed, the experience of the anaesthesiologist, dexterity of surgeons, and availability of drugs. Also, it is important where the patient lives, or if he/she are tourist patients from a remote place.

The anaesthetic profile of each intrathecal drug is the most important parameter that should be considered when planning subarachnoid anaesthesia.

Local anaesthetics. Due to the unresolved dispute over local neurotoxicity of intrathecal lidocaine,[41] some researchers have attempted to determine the usefulness of other LAs in the field of ambulatory and short-stay surgery, keeping in mind that recovery time after spinal anaesthesia is important for patients, physicians, third party payers and surgical units. There are quite a few choices of LAs for outpatient and short-stay spinal anaesthesia; bupivacaine, levobupivacaine, ropivacaine, mepivacaine, prilocaine, chloroprocaine, procaine, articaine, and lidocaine.[3,42,43] 


\begin{tabular}{lll}
\hline & Local anaesthetics & Adjuvants \\
\hline Amino-ester & Amino-amide & \\
\hline Procaine & Lidocaine & Fentanyl \\
\hline Tetracaine & Articaine & Sufentanyl \\
\hline & Bupivacaine & Morphine \\
\hline & Levobupivacaine & Clonidine \\
\hline & Ropivacaine & Dexmedetomidine \\
\hline & Mepivacaine & \\
\hline & Prilocaine & \\
\hline & Etidocaine & \\
\hline
\end{tabular}

Table 4. Drugs for spinal anaesthesia for ambulatory and short-stay plastic surgery procedures

The amino-amide pipecoloxylidides (PPX) family of LAs incorporate four drugs: racemic bupivacaine, mepivacaine, ropivacaine and levobupivacaine. All of them are used in spinal anaesthesia for ambulatory cases, in particular bupivacaine. Changes in the total dose and/or adding some adjuvant drugs has been a growing field in this line of research/clinical practice. Ropivacaine and levobupivacaine have not been approved all over the world for intrathecal use, however, multiple reports and the fact that they are made preservatives free make them safe when injected inside the spinal space.[43,44,45]

In the following paragraphs we briefly review some LAs used in spinal anaesthesia for outpatient and short-stay cases in various surgical procedures, and analyze their results to use them in ambulatory and brief-stay plastic surgery patients. We describe the amide class of LAs first, followed by the ester type.

Lidocaine. Is the most studied/used LA. During the last two decades there has been an increase in the number of patients implicating lidocaine as a possible source of neurotoxicity resulting in temporary and permanent neurologic damage after subarachnoid anaesthesia. Nowadays cauda equina is seldom reported after spinal lidocaine, but TNS are the most reported deleterious side effects. The risk to develop TNS is significantly higher after spinal lidocaine compared to spinal bupivacaine, prilocaine, procaine, levobupivacaine, ropivacaine, and chloroprocaine (7.31 (95\% confidence interval (CI) 4.16 to 12.86).[46] Fortunately, TNS symptoms last no more than five days, without permanent neural damage. Among other causes, early ambulation is one of the factors that has been associated with the development of toxicity symptoms, so in ambulatory and short-stay patients spinal lidocaine could be contraindicated.

Although spinal lidocaine use is controversial, some authors still use it for short procedures. A dose of $40 \mathrm{mg}$ is sufficient and compared with $7.5 \mathrm{mg}$ of bupivacaine.[19] A dose of $15 \mathrm{mg}$ of lidocaine plus $15 \mu \mathrm{g}$ of sufentanyl produces excellent anaesthesia and recovery time better than $50 \mathrm{mg}$ of lidocaine alone, however 50\% develops pruritus.[47] Frey et al compared in 
healthy volunteers [48] $100 \mathrm{mg}$ of lidocaine, bupivacaine $15 \mathrm{mg}$ and $15 \mathrm{mg}$ of tetracaine-the three hyperbaric-and found that lidocaine has the best recovery profile, although there were patient dependent variables between the three studied LAs, with some subjects recovering quickly among those treated with bupivacaine or tetracaine. No major differences were found between $80 \mathrm{mg}$ of either spinal isobaric lidocaine $2 \%$ or spinal isobaric mepivacaine $2 \%$ for ambulatory arthroscopic surgery. Neither group had TNS.[49] Prilocaine, mepivacaine, articaine, bupivacaine, ropivacaine, and procaine at low doses have been suggested as alternatives to spinal lidocaine.

Articaine. A 4-methyl-3(2-[propylamino] propionamido)-2-thiophenecarboxylic acid, methyl ester hydrochloride, originally named carticaine was first prepared by Rusching et al in 1969 . Introduced in dentistry in 1973, it entered clinical practice in Germany in 1976 under the changed name of articaine. It is the only amide LA that contains a thiophene ring and an additional ester ring. Recent investigations have demonstrated its usefulness in spinal anaesthesia for ambulatory short cases. In addition to its fast onset and short duration of motor blockade, it has low local neurotoxicity.[50,51,52] Doses from 50 to $80 \mathrm{mg}$ of $2 \%$ or $3 \%$ plain or hyperbaric articaine produces satisfactory anaesthesia for about 1 hour, with full recovery in 3.5 hours. Hyperbaric articaine was compared with hyperbaric bupivacaine in similar surgeries, and the results have shown a quicker onset of sensory and sympathetic block in the articaine group than in the bupivacaine group, but hypotension was more frequent and faster with articaine.[53] Hendriks et al [54] compared $50 \mathrm{mg}$ of plain articaine versus $50 \mathrm{mg}$ of plain prilocaine in day-case knee arthroscopy patients and found that full motor function recovery was shorter after articaine than prilocaine [mean (SD) 140 [33] versus 184 [46] min, respectively, $p<0.001]$. Time to spontaneous voiding was shorter after articaine than prilocaine [mean (SD) 184 [39] versus 227 [45] min, respectively, $p<0.001$ ]. One patient in the articaine group reported mild TNS limited to the first postoperative day, but there were no significant differences in adverse effects between the groups.[50] Addition of fentanyl $10 \mu \mathrm{g}$ improved analgesia and reduced postoperative analgesic consumption without prolonging motor block nor delaying total recovery.[55,56]

Bupivacaine. Is an old drug that has stood the test of time. It is a racemic LA containing two stereoisomers, $\mathrm{S}$ and $\mathrm{R}^{+}$, the latter being the most toxic. Since the controversy of spinal lidocaine neurotoxicity, bupivacaine is probably the more used LA in subarachnoid anaesthesia. Its intrathecal potency is similar to levobupivacaine and stronger than ropivacaine: ratios are 0.97 (95\% CI: 0.81-1.17) for levobupivacaine/bupivacaine, 0.65 (95\% CI: 0.54-0.80) for ropivacaine/ bupivacaine, and 0.68 (95\% CI: 0.55-0.84) for ropivacaine/levobupivacaine.[57] Although it is an adequate substitute for intrathecal lidocaine for outpatient and short-stay surgery, the usual doses of 15 to $18 \mathrm{mg}$ may be reduced 8 to $10 \mathrm{mg}$ to prevent urinary retention and delayed home discharge. In addition, almost no possibility of TNS favors the use of bupivacaine for ambulatory plastic surgery. A systematic review by Nair et al [58] suggested that 4-5 mg of hyperbaric bupivacaine can effectively produce spinal anaesthesia for knee arthroscopy with unilateral positioning. Casati et al [59] compared $8 \mathrm{mg} 0.5 \%$ hyperbaric bupivacaine versus sciatic-femoral nerve block with mepivacaine and found that to carry out peripheral nerve blocks require more time than to perform spinal anaesthesia. Patients under spinal anaesthesia 
had shorter time block, but took longer to urinate without affecting discharge time. A small dose of $4 \mathrm{mg}$ hyperbaric bupivacaine $0.25 \%$ reduces the height of sensory block and motor block duration. Doses of 3 and $4 \mathrm{mg}$ of spinal hyperbaric $0.5 \%$ bupivacaine, with fentanyl 25 $\mu \mathrm{g}$, or without the opioid can be used safely in lower extremity surgery and can provide rapid and safe release criteria.[60] Intrathecal injection of $9.7 \mathrm{mg}$ of isobaric bupivacaine acts five minutes faster than hyperbaric bupivacaine, although at 15 min level of sensory and motor block have similar characteristics of hyperbaric bupivacaine.[61] For ambulatory cosmetic short procedures doses of 8 to $10 \mathrm{mg}$ hyperbaric $0.5 \%-0.75 \%$ bupivacaine are adequate, for short-stay procedures like abdominoplasty plus breast surgery doses from 15 up to $22 \mathrm{mg}$ can be used safely, but full recovery time will be affected.

Levobupivacaine. It is the last LA introduced in clinical practice back in 1999. It is an L-stereoisomer with a longer duration of action, a clinical profile similar to racemic bupivacaine, but with less toxicity. The lethal dose of intravenous levobupivacaine is 1.3 to 1.6 times greater than racemic bupivacaine, and both have equipotent anaesthetic effect via neuroaxial. Some animal's studies have shown no damage or minimal harm to the spinal cord or cauda equina. $[62,63]$ In contrast, Takenami et al found axonal degeneration in rats injected with spinal levobupivacaine.[30] There are numerous clinical studies recommending spinal levobupivacaine in ambulatory surgery. Doses from 7.5 to $15 \mathrm{mg} 0.5 \%$ hyperbaric/isobaric levobupivacaine produced satisfactory anaesthesia. $[64,65]$ Smaller doses with added adjuvants have been reported for ambulatory cases; in gynecological patients $3 \mathrm{mg}$ along with $10 \mu \mathrm{g}$ fentanyl may be used safely,[66] 5 or $7.5 \mathrm{mg}$ 0.5\% intrathecal levobupivacaine plus fentanyl $25 \mu \mathrm{g}$ for ambulatory patients undergoing inguinal herniorraphy provides good quality spinal anaesthesia and minimizes the need for intra-operative analgesia.[67] In a double-blinded study Sanansilp et al [68] compared spinal isobaric or hyperbaric $0.42 \%$ levobupivacaine. They found that hyperbaric levobupivacaine spread higher than the isobaric form, suggesting that the former is more predictable. In elderly patients spinal levobupivacaine has better hemodynamic stability compared with bupivacaine.[69]

Although intrathecal levobupivacaine is safe, there have been reported cases of cauda equina syndrome and TNS. Twenty $\mathrm{mg}$ of isobaric levobupivacaine produce less TNS than $80 \mathrm{mg}$ of isobaric lidocaine $(0.33 \%$ versus $26.6 \%, p=0.002)$. [70] We describe a 38 year old patient who developed TNS 27 hours after abdominoplasty/liposuction done under spinal anaesthesia with $15 \mathrm{mg}$ of $0.65 \%$ hyperbaric levobupivacaine and $30 \mu \mathrm{g}$ clonidine.[71]

Ropivacaine. Identified by Ekenstam in 1957, ropivacaine was introduced in clinical loco regional and epidural anesthesia in 1997. It is the first available L-isomer LA for human use. It is less soluble than bupivacaine, and is the least toxic of the PPX family. The possibility of TNS is $0-1 \%$. Shortly after its introduction, ropivacaine was safely used for spinal anaesthesia in the ambulatory setting. It is one third less potent compared to bupivacaine or levobupivacaine.[43] Hyperbaric $0.5 \%$ ropivacaine is superior to $0.5 \%$ hyperbaric bupivacaine outpatients, since motor and sensitive block duration are significantly shorter than bupivacaine, with better cardiovascular stability.[72] Like levobupivacaine, low doses of ropivacaine are useful in outpatients; several investigative protocols reports small doses from 5 to $10 \mathrm{mg}$ were sufficient in various types of outpatient surgeries like anorectal,[73] knee arthroscopy,[74] herniorraphy. 
[75] Gautier et al [76] found that $12 \mathrm{mg}$ intrathecal ropivacaine are equivalent to $8 \mathrm{mg}$ of bupivacaine, with no additional benefits in outpatients undergoing knee arthroscopies. The accidental injection of $1.0 \%$ ropivacaine $30 \mathrm{mg}$ without serious side effects suggests us that higher doses may be used when are needed for procedures in thoracic dermatomes, even for ambulatory patients.[77]

Doses from 4 up to $30 \mathrm{mg}$ of isobaric or hyperbaric 0.75 or $1 \%$ ropivacaine can be safely used for ambulatory or short-stay plastic surgery procedures.

Mepivacaine. This LA has been used intrathecally since 1960. It has a short onset with intermediate duration and low toxicity. Its hepatic metabolism is fast and is excreted by the kidneys. Its clinical profile is similar to lidocaine, with a relative potency of 1.3:1. Spinal mepivacaine produces neurological tissue damage with infiltration of macrophages and destruction of the myelin sheaths and axons in rats. The damage was localized in the proximal portion of the posterior nerve roots, the entry zone into the spinal cord, or the fasciculus gracilis of the posterior white mater.[28] Transient neurological symptoms occurs between 0 and $30 \%$. A study of 1273 ambulatory patients managed with mepivacaine $1.5 \%$ intrathecal-epidural or intrathecal showed that $1.7 \%$ of spinal anaesthesia were inadequate and $6.4 \%$ had TNS. The average age of patients who developed TNS was $48 \pm 14$ years), significantly older than those who had not TNS $(41 \pm 16)(p<0.001)$.[78] Pawlowski et al [79] prospectively studied the anaesthetic recovery profile in 60 outpatients managed with 60 and $80 \mathrm{mg}$ intrathecal mepivacaine and concluded that both doses are adequate, although patients who were managed with $60 \mathrm{mg}$ recovered faster (20 to 30 minutes) without any side effects. The same authors found no major differences between lidocaine and mepivacaine spinal anaesthesia; time to ambulation and voiding were longer in patients who received mepivacaine as was time to epidural first dose. Neither group had TNS symptoms. Lidocaine and mepivacaine are both appropriate spinal anaesthetics for ambulatory orthopedic lower extremity procedures.[80] Adding fentanyl $10 \mu \mathrm{g}$ to $30 \mathrm{mg}$ isobaric spinal mepivacaine $1.5 \%$ produces reliable anaesthesia, hastens block regression, shortens recovery, and facilitates earlier ambulation for patients undergoing unilateral knee arthroscopy.[81]

2-Chloroprocaine. It is an ester LA suitable for short procedures under spinal anaesthesia. Preservative free chloroprocaine has been used instead of intrathecal lidocaine in order to avoid TNS. It has an antagonistic effect on $\mathrm{k}$ and $\mu$ opioid receptors, which may interfere with neuroaxial opioid administration. Spinal 2-chloroprocaine, $10 \mathrm{mg} / \mathrm{mL} \mathrm{35,} \mathrm{40,} \mathrm{45,} 50$ and $60 \mathrm{mg}$ provide consistent sensory and motor block for ambulatory surgery, while reducing the doses to 35 and $40 \mathrm{mg}$ resulted in a spinal block with faster ambulation. Even though $20 \mathrm{mg}$ and 30 mg doses can produce adequate sensory anaesthesia for short surgical procedures, less motor block and some sacral sparing should be anticipated. Most studies recommend doses from 30 to $60 \mathrm{mg}$. A dose of $10 \mathrm{mg}$ produces brief and inconsistent sensory anaesthesia, it can be considered a no effect dose.[82] Hejtmanek and Pollock [83] review 503 ambulatory patients managed with spinal chloroprocaine (median dose $40 \mathrm{mg}$, range 20-60 mg) and found that times from injection to ambulation and discharge were $107 \pm 24$ and $171 \pm 45 \mathrm{~min}$, respectively, shorter than spinal lidocaine $(155 \pm 40$ and $224 \pm 57 \mathrm{~min})(p<0.05)$, with no reports of TNS. 
Compared with $40 \mathrm{mg}$ articaine, $40 \mathrm{mg}$ of chloroprocaine had similar onset and maximal spread, but recovery from motor block was clearly faster with chloroprocaine.[84] Adding fentanyl appears to lengthen the surgical block without prolonging discharge time. Five possible cases of TNS following spinal chloroprocaine in over 4000 patients, and a regressive incomplete cauda equina syndrome have been described.[85] To sum up, the short duration of spinal chloroprocaine makes it a strong contender for outpatient anaesthesia. It appears to have a lower risk of TNS than lidocaine.

Procaine. This amino-ester LA has been used in the subarachnoid space for short surgeries since the beginning of last century. Its onset of action is slower than chloroprocaine, and only lasts 30 to 60 minutes. Although procaine produces local toxicity, it is the least neurotoxic LA when injected inside the spinal space.[28] TNS have an incidence 0 to $6 \%$. Johnson and Swanson [86] reported a patient with permanent cauda equina syndrome after $150 \mathrm{mg}$ of $10 \%$ procaine. Hodgson [87] used $100 \mathrm{mg}$ hyperbaric spinal procaine versus $50 \mathrm{mg}$ hyperbaric lidocaine in outpatient arthroscopy and found that the first had a higher rate of anaesthetic failure $(17 \%$ versus $3 \%$ ), and higher incidence of nausea (17\% versus 3\%). TNS incidence was lower with procaine ( $6 \%$ vs. $24 \%$ ). Procaine has been considered as an acceptable alternative to intrathecal lidocaine in ambulatory patients.

When choosing a LA for subarachnoid anaesthesia it is important to keep in mind that hyperbaric forms have a wider intrathecal diffusion compared to isobaric solutions, and therefore they are useful for higher dermatomes surgical procedures. The isobaric LAs are better for pelvic and lower extremity surgeries. Epinephrine is no longer recommended since it lengthens recovery time. It is always wise to consider that operating time is longer than the surgeon's estimate, as there are many timeouts prolonging the surgery. Furthermore, sometimes the original cosmetic surgical plans are modified during surgery, thereby prolonging the surgical procedure.[3] Tables 5 and 6 shows LAs and adjuvants mixtures according to the expected operating times. Note that this includes surgeries less than an hour long, which is uncommon (review of scars, liposuction of small areas, perineal). For these ultra short cases the combination of procaine+clonidine+fentanyl is excellent, without the ghost of TNS. Low doses of PPX local anaesthetics are good, but usually last longer and in a very busy facility, could prolong discharge. Doses 5 to $8 \mathrm{mg}$ of ropivacaine, bupivacaine or levobupivacaine provide up to 150 minutes of intrathecal anaesthesia. This is sufficient time for most outpatient procedures in cosmetic surgery. Prolongation of the action of the LAs by adding clonidine is dose related; 150 to $300 \mu \mathrm{g}$ can prolong spinal anaesthesia up to 4-5 hours. Drowsiness, bradycardia and hypotension are more frequent with the higher doses, but easy to treat.

In our Plastic Surgery Center the most used spinal LA for ambulatory and short-stay patients are hyperbaric bupivacaine $0.5 \%$ and $0.75 \%$, hyperbaric ropivacaine $0.75 \%$, and hyperbaric levobupivacaine $0.5 \%$. We avoid the use of intrathecal lidocaine. For brief ambulatory cases we prefer to use low dose of any PPX family LA, plus clonidine 30 to $50 \mu \mathrm{g}$. If the ambulatory procedure is over two hours it is advisable to use regular doses of LAs, and add clonidine in doses from 75 up to $150 \mu \mathrm{g}$. We do not recommend spinal opioids in ambulatory cases given the likelihood of pruritus and urinary retention. For short-stay long procedures we use 
hyperbaric bupivacaine 15 to $25 \mathrm{mg}$, hyperbaric ropivacaine 15 to $30 \mathrm{mg}$, or hyperbaric levobupivacaine $15 \mathrm{up}$ to $25 \mathrm{mg}$. Most of our short-stay patients also receive spinal clonidine 150 to $300 \mu \mathrm{g}$, with or without fentanyl 12.5 to $25 \mu \mathrm{g}$, or sufentanyl $10 \mu \mathrm{g}$. Morphine (100 to $200 \mu \mathrm{g}$ ) is seldom used, even in short-stay patients.

\begin{tabular}{|c|c|c|c|c|}
\hline \multirow[t]{2}{*}{ Surgery } & \multicolumn{4}{|c|}{ Local anaesthetic concentration and total dose in $\mathrm{mg}$} \\
\hline & Ropivacaine $0.75 \%$ & $\begin{array}{l}\text { Levobupivacaine } \\
0.75 \%\end{array}$ & Bupivacaine 0.5 a $0.75 \%$ & Lidocaine $2 \%$ ** \\
\hline $\begin{array}{l}\text { Liposucction with } \\
\text { buttocks fat grafting }\end{array}$ & 10 a 22.5 & $7.5-18$ & $7.5-15$ & $50-100$ \\
\hline Liposculpture & 10 a 22.5 & $7.5-18$ & $7.5-15$ & $50-100$ \\
\hline Buttocks implants & 15 & 10 & 10 & 100 \\
\hline Calf implants & 15 & 10 & 10 & 100 \\
\hline $\begin{array}{l}\text { Breast implants } \\
\text { combined with body } \\
\text { liposuction }{ }^{\circ}\end{array}$ & 22.5 & 18 & 18 & No \\
\hline $\begin{array}{l}\text { * Hyperbaric local ana } \\
\text { ** Not recommended }\end{array}$ & etics. The addition of & adjuvants depends & In the expected time of surge & \\
\hline
\end{tabular}

Table 5. Outpatient plastic surgery procedures and doses of intrathecal local anesthetics *

\begin{tabular}{ll}
\hline \multicolumn{1}{c}{ Estimated surgery time } & \multicolumn{1}{c}{ Drugs recommended } \\
\hline \multirow{3}{*}{ Up to one hour } & Lidocaine + clonidine \\
& Aidocaine + fentanyl \\
& Chlicaine + fentanyl \\
& Small doses of PPX + fentanyl or clonidine \\
\hline One to two hours & PPX + clonidine or fentanyl \\
\hline \multirow{2}{*}{ Two to four hours } & PPX + clonidine or fentanyl \\
& PPX + clonidine + fentanyl \\
\hline \multirow{2}{*}{ More than 4 hours } & PPX + clonidine + fentanyl \\
\hline PPX=Racemic bupivacaine, Levobupivacaine, Ropivacaine, or Mepivacaine \\
\hline
\end{tabular}

Table 6. Recommended drug combination for spinal anaesthesia according with expected surgery time 


\section{Adjuvant drugs}

Adjuvant drugs for spinal anaesthesia in outpatients and short-stay cases are a usual routine in our daily practice in order to decrease the dose of LAs, facilitate a faster recovery and effective postoperative analgesia. There are numerous receptors which modulate spinal pain response, however, there are only a few drugs for subarachnoid use acting as adjuvants. Adrenaline was the most widely used adjuvant in spinal anaesthesia before the use of neuroaxial opioids. Its use has been questioned because 100-300 $\mu$ g added to LAs did not prolong spinal anaesthesia, but delays recovery. There are some intrathecal adjuvants that have not been approved to be used in spinal anaesthesia like midazolam, ketamine and neostigmine. They may also improve the quality of block and prolong analgesia. Intrathecal magnesium sulphate mainly potentiates the analgesic action of intrathecal opioids, without significant side effects. A positive impact on spinal analgesia has also been suggested for intrathecal calcium channel blockers, and nonsteroidal anti-inflammatory drugs. Alpha2 agonists and opioids are the most used spinal adjuvants drugs.

Alpha2 agonists. Alpha2 agonists drugs are being increasingly used in critical care and anaesthesia. Beside analgesia and sedation, they also decrease sympathetic tone and attenuate the stress response to anaesthesia and surgery. Historically, adrenaline was the first alpha2 agonist used intrathecally but it is no longer recommended. Clonidine and dexmedetomidine are also members of this group of adjuvant drugs. Their site of action involves specific receptors of the spinal dorsal horn and supraspinaly in the nucleus coereleus in the pons. Spinal injection of clonidine and dexmedetomidine enhance duration and quality of subarachnoid anaesthesia without neurotoxicity. Continuous administration of spinal clonidine in Wistar rats during 14 days failed to demonstrate neurotoxic damage.[88] Erddivanli and coworkers injected male Sprague-Dawley rats [89] with $3 \mu \mathrm{g}$ and $10 \mu \mathrm{g}$ of intrathecal dexmedetomidine added to bupivacaine found no apparent pathohistological changes 24 hours after a single injection. In male Kunming mice 1 to $3 \mu \mathrm{g}$ of dexmedetomidine displayed a robust analgesia via a $\alpha 2-$ receptor in a dose dependent manner and no significant pathological impacts on the spinal cord were noticed, with a potential protective effects of lidocaine induced neural cell damage. [90]

Clonidine. Is an alpha2 agonist used in anaesthesia for various purposes. When injected neuroaxialy, it prolongs sensory and motor block, increases sedation and may potentiate hypotension and bradycardia. It has been extensively studied in high $(>150 \mu \mathrm{g})$, low $(<150$ $\mu \mathrm{g})$ and small $(<75 \mu \mathrm{g})$ doses. Doses of 150,300 and $450 \mu \mathrm{g}$ produce dose dependent analgesia, [91] and enhance spinal anaesthesia, with relative hemodynamic stability. Doses of 15 and 30 $\mu \mathrm{g}$ in addition to $11 \mathrm{mg}$ of spinal hyperbaric bupivacaine [92] provide better sensory and motor block compared to bupivacaine alone, but clonidine $30 \mu \mathrm{g}$ was associated with more incidence and duration of hypotension. Mirivirta et al used $15 \mu \mathrm{g}$ of clonidine in lateral spinal anesthesia with hyperbaric bupivacaine $5 \mathrm{mg}$ [93] in outpatients undergoing knee arthroscopy reporting intensified spinal lateral anaesthesia without affecting home-readiness. A systematic review [94] including 1,445 patients using a wide variety of spinal clonidine doses as adjuvant to subarachnoid bupivacaine, mepivacaine, prilocaine, or tetracaine found that 15 to $150 \mu \mathrm{g}$ 
prolonged in a linear, dose-dependent manner, the time to 2 segment regression (range of means, 14 to 75 minutes) and also delayed the time to regression to L2 (range of means, 11 to 128 minutes). The time to first analgesic request (median 101 minutes, range 35 to 310) and of motor block (median 47 minutes, range 6 to 131) was extended with no relation to dose. There were fewer episodes of intraoperative pain with clonidine (relative risk, 0.24 ; $95 \%$ confidence interval [CI], 0.09-0.64; number needed to treat, 13) but more episodes of arterial hypotension (relative risk, 1.81; 95\% CI 1.44-2.28; number needed to harm, 8) without evidence of doseresponsiveness. The risk of bradycardia was unchanged.

The optimal dose of spinal clonidine remains unknown. In our current practice, for short ambulatory procedures we use clonidine 30 to $50 \mu \mathrm{g}$ added to LA without negative impact on home discharge criteria. For short-stay plastic surgery we use from $75 \mathrm{up}$ to $300 \mu \mathrm{g}$ of clonidine as adjuvant for any PPX family local anaesthetics.

Dexmedetomidine. Is the newest agent in this group. It was approved by FDA in 1999 for use in humans for analgesia and sedation in the intubated patients at the intensive care settings. It has a $\alpha_{2} / \alpha_{1}$ selectivity ratio which is eight to 10 times higher than that of clonidine. Although it has not been approved for spinal use, there is some research that shows its safety and effectiveness by prolonging time of sensory and motor block of subarachnoid anaesthesia. Kanasi and coworkers [95] compared spinal dexmedetomidine $3 \mu \mathrm{g}$ versus spinal clonidine $30 \mu \mathrm{g}$ added to $12 \mathrm{mg}$ subarachnoid bupivacaine versus plain bupivacaine. They found that both alfa2 agonists shorten onset time of motor block and significantly prolonged sensory and motor times. The mean time of sensory regression to the $S 1$ segment was $303 \pm 75$ minutes in dexmedetomidine patients, $272 \pm 38$ minutes in those who received clonidine and $190 \pm 48 \mathrm{~min}$ in control group. The regression of motor block to Bromage 0 was $250 \pm 76$ minutes in dexmedetomidine group, $216 \pm 35$ minutes in clonidine cases and $163 \pm 47$ minutes in control group. The onset and regression times were not significantly different between groups treated with both alfa2 agonists. The mean arterial pressure, heart rate and level of sedation were similar in the three groups intraoperatively and postoperatively. Five $\mu \mathrm{g}$ of dexmedetomidine added to 0.75 isobaric ropivacaine prolonged duration of motor and sensory block, and enhance post operatory analgesia,[96] and significantly prolonged sensory and motor block and reduced demand of rescue analgesics in 24 hours when compared with $25 \mu \mathrm{g}$ fentanyl and $30 \mu \mathrm{g}$ clonidine when added to $12.5 \mathrm{mg}$ hyperbaric bupivacaine for spinal anaesthesia.[97] In elderly patients managed with $6 \mathrm{mg} 0.5 \%$ spinal bupivacaine, the addition of only $3 \mu \mathrm{g}$ of dexmedetomidine accelerated the blockade onset and prolonged the duration of anaesthesia and postoperative analgesia, although recovery of motor block was affected.[98]

It has been shown that intravenous dexmedetomidine and clonidine significantly prolong bupivacaine spinal anaesthesia, with good sedation effect and hemodynamic stability. In 2003 Rhee et al [99] published the first clinical article with intravenous clonidine to prolong spinal anaesthesia; iv. clonidine $3 \mu \mathrm{g} / \mathrm{kg}^{-1}$ during $10 \mathrm{~min}$ immediately after the subarachnoid block or at $50 \mathrm{~min}$ after spinal anaesthesia, prolonged significantly duration of motor and sensory block for approximately one hour. In 2007 we found that dexmedetomidine i.v. also improves bupivacaine spinal anaesthesia.[100] In our research we use an i.v. infusion of $1 \mu \mathrm{g} / \mathrm{Kg}$ dexmedetomidine given in $20 \mathrm{~min}$, followed by $0.5 \mu \mathrm{g} / \mathrm{kg} / \mathrm{h}$ dexmedetomidine drip until end 
of surgery. A comparative group was treated with clonidine $4 \mu \mathrm{g} / \mathrm{kg}$, given in $20 \mathrm{~min}$ i.v. infusion started $20 \mathrm{~min}$ after the spinal block, and followed by a $0.9 \%$ saline drip until the end of surgery. Sensory block duration was longer in both groups, $208 \pm 43.5$ and $225 \pm 58.8 \mathrm{~min}$ respectively, vs. placebo group $137 \pm 121.9 \mathrm{~min}(p=0.05)$. Motor block duration was longer in clonidine than dexmedetomidine $(191 \pm 49.8$ and $172 \pm 36.4)$ vs. placebo group $(172 \pm 36.4)$ without significative statistical difference. Other authors have confirmed our initial results using i.v. dexmedetomidine doses from 0.25 to $0.5 \mu \mathrm{g} / \mathrm{kg}$ as an initial bolus, followed or not by an infusion of $0.5 \mu \mathrm{g} / \mathrm{kg} / \mathrm{h}$.[101, 102, 103] Two meta-analysis [104,105] showed that i.v. dexmedetomidine prolonged the duration of spinal anaesthesia and improved postoperative analgesia without increasing the incidence of hypotension and adverse events. Transient reversible bradycardia was a mild side effect.

Opioids. Since Yask and Rudy demonstrated that intrathecal opioids produced potent and selective analgesia, neuroaxial opioids are the drugs most used for this purpose. All opioids administered intrathecally will produce some degree of spinally mediated analgesia. The major differences are related to their solubility characteristics and their effect on duration of action, clearance rate, and side effects. Experimental and clinical studies have demonstrated that after their neuroaxial injection, opioid liposolubility is inversely proportional to their spinal selectivity, which is higher for the most water-soluble drugs, morphine and hydromorphone, than for other more lipophilic drugs, such as fentanyl and sufentanyl.[107] Morphine significantly prolongs spinal analgesia and fentanyl and sufentanyl enhance and moderately prolong the sensory block without affecting motor function. Nausea, vomiting, pruritus, and urinary retention are frequent side effects, respiratory depression is seldom observed.

Morphine. Although spinal morphine is the gold standard for opioid neuroaxial post operatory analgesia, it is not the best choice for ambulatory nor short-stay surgery due to a greater incidence of adverse effects that requires cautious patient selection and monitoring. Morphine produces intense analgesia for up to 24-30 hours with doses as low as $100 \mu \mathrm{g}$. In our practice we avoid its use in plastic surgery patients.

Fentanyl. Is the most suitable opioid for ambulatory surgery patients. It has the strongest effect at the spinal cord administered spinally or epidurally, producing a short-term analgesia (1-4 hours), which is very helpful in acute postoperative pain. It has been used together with most local anaesthetics in doses from $10 \mu \mathrm{g}$ up to $25 \mu \mathrm{g}$ providing selective intra and postoperative analgesia, patient satisfaction, without delaying recovery time.[55,56,60,66,67,107,108,109,110] The most recommended doses are 20 and $25 \mu \mathrm{g}$ in different outpatient scenarios. Levobupivacaine $3 \mathrm{mg}$ plus $10 \mu \mathrm{g}$ fentanyl may be used as a suitable alternative to $10 \mathrm{mg}$ lidocaine plus $10 \mu \mathrm{g}$ fentanyl for subarachnoid anaesthesia of short duration. It achieved a clinically equivalent time for resolution of sensory block, similar intraoperative conditions, and comparable patient satisfaction.[111] The most common side effects are nausea, vomit and itching can be prevented or treated with nalbuphine, droperidol,[112], propofol or ondansetron. 


\section{Criteria for home discharge}

Outpatient plastic surgery patients managed with spinal anaesthesia must meet established home discharge criteria. The goal of these criteria is to discharge patients safely and avoid hospital readmissions due to complications. Pain, nausea, vomiting, and urinary retention are common examples. It is not entirely necessary to fulfill $100 \%$ of these home discharge standards, but patients should be warned about the gradual disappearance of spinal anaesthesia side effects, and facilitate easy communication with the surgical unit, the surgeon and anaesthesiologist. These patients require postanaesthetic and appropriate postoperative orders, transportation, and occasional professional company. It is vital that each unit defines its own ambulatory surgery discharge criteria, according to the characteristics and specific needs of their patients.[3,4] Table 7 shows the most common discharge criteria.

\begin{tabular}{ll}
\hline Hemodynamic stability & Vital signs return to pre-anaesthetic values is mandatory \\
\hline Full alertnesss & Patient awake, well oriented. Spinal anaesthesia promotes alertness which facilitates \\
\hline Permeable digestive tract & Tolerance to solid or liquid intake without nausea or vomiting \\
\hline Without or mild pain & Controlled postoperative pain (VAS <2/10) with oral analgesics. Spinal anaesthesia \\
& with adjuvants provides an extended period of analgesia, it does facilitate early \\
& home discharge and reduce analgesics needs.lt is desirable to prescribe a \\
& combination of opioid and non-opioid analgesics for expected postoperative pain \\
& and patient profile. \\
\hline Spontaneous bladder voiding & This is a controversial requirement. Some centers consider it as mandatory to prevent \\
& readmissions for distended bladder. In our practice we do not consider this \\
& requirement as essential and the patient knows the remote possibility of urinating \\
& difficulties. We avoid the use of intrathecal opioids to reduce this risk. \\
\hline Ability to walk & Complete regression of motor block is convenient. The patient may try to walk when \\
& perianal sensitivity has been recovered, and is able to flex and extend the foot. In \\
some cases it is feasible to discharge without 100\% motor recovery.
\end{tabular}

Table 7. Home discharge criteria

\section{Conclusions}

Outpatient and short-stay plastic surgery cases have grown exponentially worldwide. Anaesthesiologists need to provide a safe anaesthesia to these patients who are often subjected 
to prolonged surgeries with risks that are higher than expected. Nowadays most cosmetic operations can be done in outpatient and short-stay facilities thanks to advances in anaesthesia. Although most anesthesiologists use general anesthesia for these procedures, regional anesthesia techniques have demonstrated certain advantages such as better pain control, attenuation of the surgical stress response, preserves perioperative immune function, better preservation of oxygenation and lung residual functional capacity, improved visceral vascular flow, less bleeding, early recovery of postoperative ileum, and reduced venous thrombotic disease and pulmonary embolism.

Spinal anaesthesia is a simple technique, with a small volume of drugs producing profound anaesthesia and analgesia, and is devoid of systemic pharmacologic side effects. There are many choices of LAs for outpatient and short-stay spinal anaesthesia; for ultra short procedures the best choice are procaine, articaine or lidocaine. For intermediate duration procedures small doses of intermediate duration LAs, or even lidocaine can be used. For longer procedures bupivacaine, levobupivacaine, and ropivacaine are excellent agents. Addition of adjuvant drugs to LAs enhance subarachnoid anaesthesia with better recovery according with expected surgical time, low incidence of side effects or complications, and longer postoperative analgesia. Clonidine and dexmedetomidine accelerate the onset and prolong the duration of spinal anaesthesia and analgesia.

Severe complications after spinal anesthesia are exceedingly rare; cardiac arrest, meningitis, intracranial subdural hematoma, spinal epidural hematoma, TNS and cauda equina syndrome. Patients should be informed in detail regarding the incidence, severity, and outcome of these complications.

\section{Author details}

Víctor M. Whizar-Lugo ${ }^{1}$, Juan C. Flores-Carrillo², Susana Preciado-Ramírez ${ }^{3}$, Jaime Campos-León ${ }^{4}$ and Víctor Silva ${ }^{5}$

1 Anesthesiology, Pain Medicine and Critical Care Medicine, Investigador Asociado C, Institutos Nacionales de Salud, Anestesiología y Medicina del Dolor, Centro Médico del Noroeste, Tijuana BC, México

2 Anesthesiology and Critical Care Medicine, Centro Médico del Noroeste, Tijuana BC, México 3 Anesthesiology, Fundación Médica Sur, Ciudad de México, México

4 Campos-León Plastic Surgery Center, Tijuana, México

5 Anesthesiology and Pain Medicine, Hospital Universitario Dr. José Eleuterio González, Monterrey NL, México 


\section{References}

[1] Shapiro FE. Anesthesia for outpatient cosmetic surgery. Curr Opin Anaesthesiol. 2008;21:704-10.

[2] Hafezi F, Naghibzadeh B, Nouhi AH, Salimi A, Naghibzadeh G, Mousavi SJ. Epidural anesthesia as a thromboembolic prophylaxis modality in plastic surgery. Aesthet Surg J. 2011;31:821-4.

[3] Whizar-Lugo VM, Cisneros-Corral R, Reyes-Aveleyra MA, Campos-León J, Shakhov A. Anestesia subaracnoidea en cirugía plástica ambulatoria. Anest Mex 2008;20:23-33.

[4] Whizar-Lugo V, Cisneros-Corral R, Reyes-Aveleyra MA, Campos-León J. Domínguez J. Anesthesia for plastic surgery procedures in previously morbidly obese patients. Anest Mex 2009;21:186-193.

[5] Dini GM, Ferreira MC, Albuquerque LG, Ferreira LM. How safe is thromboprophylaxis in abdominoplasty? Plast Reconstr Surg. 2012;130:851e-857e.

[6] Neaman KC, Hansen JE.Analysis of complications from abdominoplasty: a review of 206 cases at a university hospital. Ann Plast Surg. 2007;58:292-8.

[7] Pannucci CJ, Bailey SH, Dreszer G, et al. Validation of the Caprini risk assessment model in plastic and reconstructive surgery patients.J Am Coll Surg. 2011;212:105-12.

[8] Rawal N, Holmström B. The combined spinal--epidural technique. Best Pract Res Clin Anaesthesiol. 2003;17:347-64.

[9] Kodeih MG, Al-Alami AA, Atiyeh BS, Kanazi GE. Combined spinal epidural anesthesia in an asthmatic patient undergoing abdominoplasty. Plast Reconstr Surg. 2009;123:118e-120e.

[10] Svetlov VA, Kozlov SP, Vashchinskaia TV, Sarkisova NG. Subarachnoidal anesthesia: the limits of its potentials. Anesteziol Reanimatol. 1999;5:38-44.

[11] Whizar LV, Carrada PS, Cisneros CR, Cortes GC, Solar LC. Migración subaracnoidea del catéter o del anestésico durante anestesia epidural-espinal combinada. Informe de un caso. Rev Mex Anest 1997;20:91-5.

[12] Dean HP. Discussion on the relative value of inhalation and injection methods of inducing anaesthesia. Br Med J 1907;5:869-77.

[13] Lemmon WT. A method for continuous spinal anesthesia: A preliminary report. Ann Surg. 1940;111:141-4.

[14] Hurley RJ, Lambert DH. Continuous spinal anesthesia with a microcatheter technique: preliminary experience. Anesth Analg. 1990;70:97-102. 
[15] Lux EA. Continuous spinal anesthesia for lower limb surgery: a retrospective analysis of 1212 cases. Local Reg Anesth. 2012;5:63-7.

[16] Dhami LD. Liposuction. Indian J Plast Surg. 2008;41(Suppl):S27-40.

[17] Whizar LV, Cisneros CR, Reyes AMA, Ontiveros MP. Combined lumbar spinal-epidural anaesthesia (CLSEA) with hyperbaric $0.75 \%$ ropivacaine plus clonidine for breast and abdominal-pelvic plastic surgery. An open trial. WCA Paris, France. 2004;CD231.

[18] Di Cianni S, Rossi M, Casati A, Cocco C, Fanelli G. Spinal anesthesia: an evergreen technique. Acta Biomed. 2008;79:9-17.

[19] Liu SS.Optimizing spinal anesthesia for ambulatory surgery. Reg Anesth. 1997;22:500-10.

[20] Casati A, Vinciguerra F. Intrathecal anesthesia. Curr Opin Anaesthesiol. 2002;15:543-51.

[21] Urmey WF. Spinal anaesthesia for outpatient surgery. Best Pract Res Clin Anaesthesiol. 2003;17:335-46.

[22] Pitkänen MT, Aromaa U, Cozanitis DA, Förster JG. Serious complications associated with spinal anaesthesia in Finlad from 2000 to 2009. Acta Anaesthesiol Scand. 2013;57:553-64.

[23] Pollard JB.Cardiac arrest during spinal anesthesia: common mechanisms and strategies for prevention. Anesth Analg. 2001;92:252-6.

[24] Limongi JA, Lins RS.Cardiopulmonary arrest in spinal anesthesia. Rev Bras Anestesiol. 2011;61:110-20.

[25] Auroy Y, Narchi P, Messiah A, Litt L, Rouvier B, Samii K. Serious complications related to regional anesthesia: results of a prospective survey in France. Anesthesiology. 1997;87:479-86.

[26] Takenami T, Yagishita S, Asato F, Arai M, Hoka S. Intrathecal lidocaine causes posterior root axonal degeneration near entry into the spinal cord in rats. Reg Anesth Pain Med. 2002;27:58-67.

[27] Schneider M, Ettllin T, Kaufmann M. et al. Transient neurologic toxicity after hyperbaric subarachnoid anesthesia with 5\% lidocaine. Anest Analg 1993:76;1154-57.

[28] Takenami T, Yagishita S, Nara Y, et al. Spinal procaine is less neurotoxic than mepivacaine, prilocaine and bupivacaine in rats. Reg Anesth Pain Med. 2009;34:189-95.

[29] Takenami T, Yagishita S, Murase S, et al. Neurotoxicity of intrathecally administered bupivacaine involves the posterior roots/posterior white matter and is milder than lidocaine in rats. Reg Anesth Pain Med. 2005;30:464-72. 
[30] Takenami T, Wang G, Nara Y, et al. Intrathecally administered ropivacaine is less neurotoxic than procaine, bupivacaine, and levobupivacaine in a rat spinal model. Can J Anaesth. 2012;59:456-65.

[31] Zhong Z, Qulian G, Yuan Z, Wangyuan Z, Zhihua S. Repeated intrathecal administration of ropivacaine causes neurotoxicity in rats. Anaesth Intensive Care. 2009;37:929-36.

[32] Rätsch G, Niebergall H, Hauenstein L, et al. Spinal anaesthesia in day-case surgery. Optimisation of procedures. Anaesthesist 2007;56:322-27.

[33] Carrada PS, Whizar LV, Pérez OA, Cabrera MN. Incidencia de cefalea postraquia en pacientes jóvenes. Estudio doble ciego, comparativo con Atraucan 26, Quincke 26 y Whitacre 27. Rev Mex Anest 1997;20:3-10.

[34] Reina MA, De Leon O, Lopez A, De Andres J, Martin S, Mora M. An in vitro study of dural lesions produced by 25-gauge Quincke and Whitacre needles evaluated by scanning electron microscopy. Reg Anesth Pain Med 2000;25:393-402.

[35] Fettes PDW, Jansson JR, Wildsmith JAW. Failed spinal anaesthesia: mechanisms, management, and prevention. Brit J Anaesth 2009;102:739-48.

[36] Abouleish E. How to proceed following a ${ }^{\circ}$ failed spinal ${ }^{\circ}$. Anesthesiology 1992;76:476-7.

[37] Drasner K, Rigler ML. Repeat injection after a failed spinal: At times, a potentially unsafe practice. Anesthesiology 1991;75:713-4.

[38] Aldrete A. Neurologic deficits and arachnoiditis following neuroaxial anesthesia. Acta Anaesthesiol Scand 2003;47:3-12.

[39] Castillo J, Santiveri X, Escolano F, et al. Incidencia de hematomas espinales con compresión medular relacionados con anestesias neuroaxiales en Cataluña. Rev Esp Anestesiol Reanim. 2007;54:591-5.

[40] Horlocker TT, Wedel DJ, Rowlingson JC, et al. Regional anesthesia in the patient receiving antithrombotic or thrombolytic therapy: American Society of Regional Anesthesia and Pain Medicine Evidence-Based Guidelines (Third Edition). Reg Anesth Pain Med. 2010;35:64-101.

[41] Förster JG, Rosenberg PH. Revival of old local anesthetics for spinal anesthesia in ambulatory surgery. Curr Opin Anaesthesiol. 2011;24:633-7.

[42] Hendriks MP, de Weert CJ, Snoeck MM, Hu HP, Pluim MA, Gielen MJ. Plain articaine or prilocaine for spinal anaesthesia in day-case knee arthroscopy: a doubleblind randomized trial. Br J Anaesth. 2009;102:259-63.

[43] Whizar LV, Carrada PS. Ropivacaína: una novedosa alternativa en anestesia regional. Rev Mex Anest 1999;22:122-152. 
[44] Wille M. Intrathecal use of ropivacaine: a review. Acta Anaesthesiol Belg 2004;55:251-9.

[45] Sanansilp V, Trivate T, Chompubai P, et al. Clinical characteristics of spinal levobupivacaine: hyperbaric compared with isobaric solution. ScientificWorld Journal. 2012;2012:169076.

[46] Zaric D, Pace NL. Transient neurologic symptoms (TNS) following spinal anaesthesia with lidocaine versus other local anaesthetics. Cochrane Database Syst Rev. 2009 Apr 15;[2]:CD003006.

[47] Waxler B, Mondragon SA, Patel SN, Nedumgottil K. Intrathecal lidocaine and sufentanil shorten postoperative recovery after outpatient rectal surgery. Can J Anaesth 2004;51:680-4.

[48] Frey K, Holman S, Mikat-Stevens M et al. The recovery profile of hyperbaric spinal anesthesia with lidocaine, tetracaine, and bupivacaine. Reg Anesth Pain Med 1998;23:159-163.

[49] Pawlowski J, Orr K, Kim KM, Pappas AL, Sukhani R, Jellish WS. Anesthetic and recovery profiles of lidocaine versus mepivacaine for spinal anesthesia in patients undergoing outpatient orthopedic arthroscopic procedures. J Clin Anesth. 2012;24:109-15.

[50] Kallio H, Snall EV, Luode T, Rosenberg PH. Hyperbaric articaine for day-case spinal anaesthesia. Br J Anaesth. 2006;97:704-9.

[51] Timmerman L, van Dongen EP, Tromp E, Andriessen EJ, Kerkvliet CT, Knibbe CA. Articaine and lidocaine for spinal anaesthesia in day case surgery. Reg Anesth Pain Med. 2007;32 Suppl 1:9.

[52] Snoeck M. Articaine: a review of its use for local and regional anesthesia. Local Reg Anesth 2012;5:23-33.

[53] Malinovsky JM. Is 4\% Articaine suitable for spinal anesthesia. Eur J Anesthesiol. 2012;29:5-6.

[54] Hendriks MP, de Weert CJ, Snoeck MM, Hu HP, Pluim MA, Gielen MJ. Plain articaine or prilocaine for spinal anaesthesia in day-case knee arthroscopy: a doubleblind randomized trial. Br J Anaesth. 2009;102:259-63.

[55] Kairaluoma P, Bachmann M, Kallio H, Rosenberg P, Pere P. Hyperbaric articaine with or without fentanyl in spinal anaesthesia: patient and observer blinded comparison. Acta Anaesthesiol Scand. 2013;57:118-25.

[56] Bachmann M, Pere P, Kairaluoma P, Rosenberg PH, Kallio H. Randomised comparison of hyperbaric articaine and hyperbaric low-dose bupivacaine along with fentanyl inspinal anaesthesia for day-case inguinal herniorrhaphy. Eur J Anaesthesiol. 2012;29:22-7. 
[57] Lee YY, Ngan Kee WD, Fong SY, Liu JT, Gin T. The median effective dose of bupivacaine, levobupivacaine, and ropivacaine after intrathecal injection in lower limb surgery. Anesth Analg. 2009;109:1331-4.

[58] Nair GS, Abrishami A, Lermitte J, Chung F. Systematic review of spinal anaesthesia using bupivacaine for ambulatory knee arthroscopy. Br J Anaesth. 2009;102:307-15.

[59] Casati A, Cappelleri G, Fanelli G, et al. Regional anaesthesia for outpatient knee arthroscopy: a randomized clinical comparison of two different anaesthetic techniques. Acta Anaesthesiol Scand 2000;44:543-7.

[60] Unal D, Ozdogan L, Ornek HD, et al. Selective spinal anaesthesia with low-dose bupivacaine and bupivacaine+fentanyl in ambulatory arthroscopic knee surgery. J Pak Med Assoc. 2012;62:313-8.

[61] Marin R, Frigon CH, Chrétien A, Tétraul JP. Onset of spinal block is more rapid with isobaric than hyperbaric bupivacaine. Can J Anesth 2000;47:43-6.

[62] Vasconcelos Filho Pde O, Posso Ide P, Capelozzi M, Capelozzi VL. Comparison of histologic spinal cord and neurologic changes in guinea pigs after subarachnoid block with large volumes of racemic bupivacaine, 50\% enantiomeric excess bupivacaine (S75-R25], and levobupivacaine. Rev Bras Anestesiol. 2008;58:234-45.

[63] Hamurtekin E, Fitzsimmons BL, Shubayev VI, et al. Evaluation of spinal toxicity and long-term spinal reflex function after intrathecal levobupivaciane in the neonatal rat. Anesthesiology. 2013;119:142-55.

[64] Burke D, Kennedy S, Bannister J. Spinal anesthesia with 0.5\% S(-)-bupivacaine for elective lower limb surgery. Reg Anesth Pain Med 1999;24:519-523.

[65] Onur O, Sibel AM, Mustafa A, Mehmet Y.Comparison of the effects of intrathecal different dosage of levobupivacaine in elective day-case arthroscopy of the knee. Middle East J Anesthesiol. 2010;20:703-8.

[66] de Santiago J, Santos-Yglesias J, Giron J, Montes de Oca F, Jimenez A, Diaz P. Lowdose $3 \mathrm{mg}$ levobupivacaine plus 10 microg fentanyl selective spinal anesthesia for gynecological outpatient laparoscopy. Anesth Analg. 2009;109:1456-61.

[67] Girgin NK, Gurbet A, Turker G, et al. The combination of low-dose levobupivacaine and fentanyl for spinal anaesthesia in ambulatory inguinal herniorrhaphy. J Int Med Res. 2008;36:1287-92.

[68] Sanansilp V, Trivate T, Chompubai P, et al. Clinical characteristics of spinal levobupivacaine: hyperbaric compared with isobaric solution. ScientificWorldJournal. 2012;2012:169076.

[69] Erdil F, Bulut S, Demirbilek S, Gedik E, Gulhas N, Ersoy MO. The effects of intrathecal levobupivacaine and bupivacaine in the elderly. Anaesthesia. 2009;64:942-6. 
[70] Gozdemir M, Muslu B, Sert H, et al. Transient neurological symptoms after spinal anaesthesia with levobupivacaine $5 \mathrm{mg} / \mathrm{ml}$ or lidocaine $20 \mathrm{mg} / \mathrm{ml}$. Acta Anaesthesiol Scand. 2010;54:59-64.

[71] Martínez-Gallegos N, Reyes-Aveleyra MA, Whizar-Lugo VM. Síndrome de irritación transitoria secundario a levobupivacaína $0.65 \%$ subaracnoidea. Informe de un caso. Anest Mex 2006;18:96-100.

[72] López-Soriano F, Lajarín B, Rivas F, Verdú JM, López-Robles J. Ropivacaína hiperbárica subaracnoidea en cirugía ambulatoria: estudio comparativo con bupivacaína hiperbárica. Rev Esp Anestesiol Reanim 2002;49:71-5.

[73] Buckenmaier CC 3rd, Nielsen KC, Pietrobon R, et al. Small-dose intrathecal lidocaine versus ropivacaine for anorectal surgery in an ambulatory setting. Anesth Analg. 2002;95:1253-7.

[74] Fanelli G, Danelli G, Zasa M, Baciarello M, Di Cianni S, Leone S. Intrathecal ropivacaine $5 \mathrm{mg} / \mathrm{ml}$ for outpatient knee arthroscopy: a comparison with lidocaine 10 mg/ml. Acta Anaesthesiol Scand. 2009;53:109-15.

[75] Taspinar V, Sahin A, Donmez NF, et al. Low-dose ropivacaine or levobupivacaine walking spinal anesthesia in ambulatory inguinal herniorrhaphy. J Anesth. 2011;25:219-24.

[76] Gautier PE, DeKock M, Van Steenberge A. Intrathecal ropivacaine for ambulatory surgery: A comparison between intrathecal bupivacaine and intrathecal ropivacaine for knee arthroscopy. Anesthesiology 1999;91:1239-1245.

[77] Whizar-Lugo VM, Martínez Gallegos N, Domínguez J. Sobredosis intratecal accidental de 30mg de ropivacaína al 1\%. Informe de un paciente. Anest Mex 2007;19:41-6.

[78] YaDeau JT, Liguori GA, Zayas VM. The incidence of transient neurologic symptoms after spinal anesthesia with mepivacaine. Anesth Analg. 2005;101:661-5.

[79] Pawlowski J, Sukhani R, Pappas AL et al. The anesthetic and recovery profile of two doses [60 and $80 \mathrm{mg}$ ) of plain mepivacaine for ambulatory spinal anesthesia. Anesth Analg. 2000;91:580-4.

[80] Pawlowski J, Orr K, Kim KM, Pappas AL, Sukhani R, Jellish WS. Anesthetic and recovery profiles of lidocaine versus mepivacaine for spinal anesthesia in patients undergoing outpatient orthopedic arthroscopic procedures. J Clin Anesth. 2012;24:109-15.

[81] O'Donnell D, Manickam B, Perlas A, et al. Spinal mepivacaine with fentanyl for outpatient knee arthroscopy surgery: a randomized controlled trial. Can J Anaesth. 2010;57:32-8.

[82] Kopacz DJ. Spinal 2-chloroprocaine: minimum effective dose. Reg Anesth Pain Med. 2005;30:36-42. 
[83] Hejtmanek MR, Pollock JE. Chloroprocaine for spinal anesthesia: a retrospective analysis. Acta Anaesthesiol Scand. 2011;55:267-72.

[84] Förster JG, Rosenberg PH, Harilainen A, Sandelin J, Pitkänen MT. Chloroprocaine 40 mg produces shorter spinal block than articaine $40 \mathrm{mg}$ in day-case knee arthroscopy patients. Acta Anaesthesiol Scand. 2013;57:911-9.

[85] Goldblum E, Atchabahian A.The use of 2-chloroprocaine for spinal anaesthesia. Acta Anaesthesiol Scand. 2013;57:545-52.

[86] Johnson ME, Swanson JW. Procaine spinal neurotoxicity. Anesthesiology. 2008;109:349-51.

[87] Hodgson PS, Liu SS, Batra MS, Gras TW, Pollock JE, Neal JM. Procaine compared to lidocaine for incidence of transient neurologic symptoms. Reg Anesth Pain Med 2000;25:218-22.

[88] Guevara-López U, Aldrete JA, Covarrubias-Gómez A, Hernández-Pando RE, LópezMuñoz FJ. Absence of histological changes after the administration of a continuous intrathecal clonidine in Wistar rats. Pain Pract. 2009;9:122-9.

[89] Erdivanli B, Altun M, Sezen OK, Colakoğlu SA. Anti-nociceptive, analgesic and pathohistological effects of intrathecal dexmedetomidine and bupivacaine in rats. Rev Bras Anestesiol. 2013;63:183-7.

[90] Zhang H, Zhou F, Li C, et al. Molecular mechanisms underlying the analgesic property of intrathecal dexmedetomidine and its neurotoxicity evaluation: an in vivo and in vitro experimental study. PLoS One. 2013;8:e55556.

[91] Filos KS, Goudas LC, Patroni O, Polyzou V. Hemodynamic and analgesic profile after intrathecal clonidine in humans. A dose-response study. Anesthesiology 1994;81:591-601.

[92] Thakur A, Bhardwaj M, Kaur K, Dureja J, Hooda S, Taxak S. Intrathecal clonidine as an adjuvant to hyperbaric bupivacaine in patients undergoing inguinal herniorrhaphy: A randomized double-blinded study. J Anaesthesiol Clin Pharmacol. 2013;29:66-70.

[93] Merivirta R, Kuusniemi K, Jaakkola P, Pihlajamäki K, Pitkänen M.Unilateral spinal anaesthesia for outpatient surgery: a comparison between hyperbaric bupivacaine and bupivacaine-clonidine combination. Acta Anaesthesiol Scand. 2009;53:788-93.

[94] Elia N, Culebras X, Mazza C, Schiffer E, Tramèr MR. Clonidine as an adjuvant to intrathecal local anesthetics for surgery: systematic review of randomized trials. Reg Anesth Pain Med. 2008;33:159-67.

[95] Kanazi GE, Aouad MT, Jabbour-Khoury SI, et al. Effect of low-dose dexmedetomidine or clonidine on the characteristics of bupivacaine spinal block. Acta Anaesthesiol Scand. 2006;50:222-7. 
[96] Gupta R, Bogra J, Verma R, Kohli M, Kushwaha JK, Kumar S. Dexmedetomidine as an intrathecal adjuvant for postoperative analgesia. Indian J Anaesth. 2011;55:347-51.

[97] Mahendru V, Tewari A, Katyal S, Grewal A, Singh MR, Katyal R. A comparison of intrathecal dexmedetomidine, clonidine, and fentanyl as adjuvants of hyperbaric bupivacaine for lower limb surgery: A double blind controlled study. J Anaesthesiol Clin Pharmacol 2013;29:496-502.

[98] Kim JE, Kim NY, Lee HS, Kil HK. Effects of intrathecal dexmedetomidine on lowdose bupivacaine spinal anesthesia in elderly patients undergoing transurethral prostatectomy. Biol Pharm Bull. 2013;36:959-65.

[99] Rhee K, Kang K, Kim J, Jeon Y. Intravenous clonidine prolongs bupivacaine spinal anesthesia. Acta Anaesthesiol Scand. 2003;47:1001-1005.

[100] Whizar-Lugo V, Gómez-Ramírez IA, Cisneros-Corral R, Martínez-Gallegos N. Intravenous dexmedetomidine vs. intravenous clonidine to prolong bupivacaine spinal anesthesia. A double blind study. Anest Mex 2007;19:143-146.

[101] Harsoor S, Rani DD, Yalamuru B, Sudheesh K, Nethra S. Effect of supplementation of low dose intravenous dexmedetomidine on characteristics of spinal anaesthesia with hyperbaric bupivacaine. Indian J Anaesth. 2013;57:265-9.

[102] Jung SH, Lee SK, Lim KJ, et al. The effects of single-dose intravenous dexmedetomidine on hyperbaric bupivacaine spinal anesthesia. J Anesth. 2013;27:380-4.

[103] Al-Mustafa MM, Badran IZ, Abu-Ali HM, Al-Barazangi BA, Massad IM, Al-Ghanem $\mathrm{SM}$. Intravenous dexmedetomidine prolongs bupivacaine spinal analgesia. Middle East J Anesthesiol. 2009;20:225-31.

[104] Abdallah FW, Abrishami A, Brull R. The facilitatory effects of intravenous dexmedetomidine on the duration of spinal anesthesia: a systematic review and meta-analysis. Anesth Analg. 2013;117:271-8.

[105] Niu XY, Ding XB, Guo T, Chen MH, Fu SK, Li Q. Effects of intravenous and intrathecal dexmedetomidine in spinal anesthesia: a meta-analysis. CNS Neurosci Ther. 2013;19:897-904.

[106] Bujedo BM, Santos SG, Azpiazu AU.A review of epidural and intrathecal opioids used in the management of postoperative pain. J Opioid Manag. 2012;8:177-92.

[107] de Santiago J, Santos-Yglesias J, Girón J, Jiménez A, Errando CL. Anestesia subaracnoidea hipobárica a dosis bajas para cirugía anorrectal en posición de navaja: comparación entre levobupivacaína-fentanilo y licocaína-fentanilo. Rev Esp Anestesiol Reanim. 2010;57:565-70.

[108] Chilvers CR, Vaghadia H, Mitchell GW, Merrick PM. Small-dose hypobaric lidocaine-fentanyl spinal anesthesia for short duration outpatient laparoscopy. II. Optimal fentanyl dose. Anesth Analg. 1997;84:65-70. 
[109] Kallio H, Snäll EV, Suvanto SJ, et al. Spinal hyperbaric ropivacaine-fentanyl for daysurgery. Reg Anesth Pain Med. 2005;30:48-54.

[110] Girgin NK, Gurbet A, Turker G, et al. The combination of low-dose levobupivacaine and fentanyl for spinal anaesthesia in ambulatory inguinal herniorrhaphy. J Int Med Res. 2008;36:1287-92.

[111] de Santiago J, Santos-Yglesias J, Giron J, Montes de Oca F, Jimenez A, Diaz P. Lowdose $3 \mathrm{mg}$ levobupivacaine plus $10 \mu \mathrm{g}$ fentanyl selective spinal anesthesia for gynecological outpatient laparoscopy. Anesth Analg. 2009;109:1456-61.

[112] Ben-David B, DeMeo PJ, Lucyk C, Solosko D. Minidose lidocaine-fentanyl spinal anesthesia in ambulatory surgery: prophylactic nalbuphine versus nalbuphine plus droperidol. Anesth Analg. 2002;95:1596-600. 